Collection: IUFRO RG 7.012010 - Antalya (Turkey)

"Adaptation of Forest Ecosystems to Air Pollution and Climate Change"

Guest Editors: Elena Paoletti, Yusuf Serengil

\title{
Air pollution regulations in Turkey and harmonization with the EU legislation
}

\section{Aydin Coskun A, Türker OY, Velioglu N}

Since the very first moment of invention of fire in the prehistoric age, atmospheric pollution has increased to such an extent that it has become a threat for human and environmental health by the mid-20th century due to factors such as industrialization, migration from rural areas to urban, rapid population growth, unplanned settlements etc. In order to avoid these harmful effects, work has been carried out at national and international level. Air pollution is an important problem in Turkey too, and legal, institutional, technical and scientific studies are being conducted. One of the essential tools to be used to solve this problem is "legal regulations". There are a vast number of legal regulations relating to this matter in Turkish environmental legislation, with Turkish Constitution of 1982 being at the first place. In addition, Turkey has commitments arising from being a party of international agreements. In EU membership process, harmonization between the EU and national legislation is in progress. In this study, commitments of Turkey arising from international agreements and EU Directives about air pollution are set forth. Then, Turkish environmental legislation about this issue is summarised. Finally, a gap analysis of Turkish air pollution legislation is performed compared to international provisions, and thus a basis is established for the legal regulations to be issued in the future.

Keywords: Environmental legislation, Air pollution, Climate change, EU, Turkey

\section{Introduction}

One of the major hazards that will affect the future generations is air pollution (Serengil et al. 2011). Air pollution in the world has reached a risky level for human life, particularly due to the rapid industrial development. In recognition of this fact, the countries over the world entered into several international conventions, the first of which was concluded in 1979, to prevent air pollution. Turkey has become a party to some of these conventions and made them an integra

$\square$ Istanbul University, Faculty of Forestry, Department of Environment and Forest Law, TR-34473 Bahcekoy, Istanbul (Turkey)

@, Özhan Y. Türker

(ozhan_turker@yahoo.com)

Received: May 04, 2011 - Accepted: May 19, 2011

Citation: Aydin Coskun A, Türker YO, Velioglu N, 2011. Air pollution regulations in Turkey and harmonization with the EU legislation. iForest 4: 181-185 [online 201108-11] URL:

http://www.sisef.it/iforest/show.php? id $=585$ part of its domestic law in accordance with article 90 , which states that “... International treaties duly put into effect have the force of law. No appeal to the Constitutional Court can be made with regard to these treaties, on the ground that they are unconstitutional. In case of any conflict between international treaties on basic rights and freedoms duly brought into force and the law on the same subject, provisions of the international treaties shall be applicable" The first convention entered into by Turkey was the Convention on Long-Range Transboundary Air Pollution (Geneva 1979, accepted by Turkey on 23.03.1983), which was followed by the Vienna Convention for the Protection of Ozone Layer (Vienna 1985, accepted by Turkey on 08.09.1990), The Montreal Convention (Montreal 16.09.1987, accepted by Turkey in 1990), United Nations Framework Convention on Climate Change (United Nations Framework Convention on Climate Change: 09.05 .1992 , accepted by Turkey on 11.11.2003) and The Kyoto Protocol to the United Nations Framework Convention on Climate Change (Kyoto Protocol, the United Nations Framework Convention on Climate Change: 11.12.1997, accepted by Turkey on 13.05.2009).
In addition to the above conventions, European Union (EU) issued several Directives on air pollution. The major regulation on this matter is the "Directive on Ambient Air Quality and Cleaner Air for Europe" (2008/50/EC). As a candidate to the EU, Turkey has no commitment arising from these Directives. However, Turkey has started negotiations on environment chapter in December 2009, and has to achieve harmonization with the $\mathrm{EU}$ acquis within the shortest time. Therefore, EU directives will also be dealt with in this paper.

Our aims are to summarise the state-of-art of the international commitments of Turkey in terms of air pollution, and provide a basis for further harmonization of national and international commitments.

\section{Air pollution in the international legislation}

In the Convention on Long-Range Transboundary Air Pollution, which is the first international convention to which Turkey has become a party, "air pollution" is defined as "the introduction by man, directly or indirectly, of substances or energy into the air resulting in deleterious effects of such a nature as to endanger human health, harm living resources and ecosystems and material property and impair or interfere with amenities and other legitimate uses of the environment" (Victor \& Coben 2005). The contracting parties "shall endeavor to limit and, as far as possible, gradually reduce and prevent air pollution including long-range transboundary air pollution". Actions and policies required to be taken and observed by the contracting parties in order to fulfill their commitments to prevent air pollution are also specified under the convention. Accordingly, the contracting parties have undertaken to develop policies and strategies at national and international levels by way of exchange of information, cooperation, research and monitoring. The ways to realize two principles within the said commitments, namely "research and development" and "exchange of information", are described. In conclusion, "preventing pollution", "exchange of information", "cooperation", "research and development" and "monitoring" principles are highlighted in the convention.

Another convention participated by Turkey is the Vienna Convention. It directly addresses the protection of ozone layer, whose depletion is due to air pollution. The contracting parties have undertaken to conduct researches and systematic observations on the subject-matter. Furthermore, the parties shall facilitate and encourage exchange of scientific, socio-economic, commercial and legal information relevant to the convention. The contracting parties have also undertaken to cooperate in order to improve data and 
technology transfer. Fields of the said cooperation have been specified as follows: "Facilitation of the acquisition of alternative technologies by other Parties, provision of information on alternative technologies and equipment and supply of special manuals or guides to them, the supply of necessary equipment and facilities for research and systematic observations, and appropriate training of scientific and technical personnel (Vienna Convention, Article 4). In addition, it is prescribed to establish a Conference of the Parties and keep under continuous review the implementation of the convention. In conclusion, the principles "research", "cooperation" and "exchange of information" are highlighted in this convention.

In 1987, the Montreal Protocol was issued based on the Vienna Convention (Benedick 1998, Beukel 2003, Gareau 2008, Mehrotra et al. 2009, Woods 2002). The "Montreal Protocol on Substances that Deplete the Ozone Layer" is the most significant and influential of all current international environmental treaties (Lin 2009). In the beginning, 60 countries executed this Protocol. The number of countries has reached 191 within the twenty years after signing of the treaty (McFarland 2007). In this protocol, to which Turkey is a party, provisions about control measures, control of trade with the non-contracting states, evaluation and review of the control measures, research, development, informing the public and exchange of information and financial mechanism have been laid down.

Turkey has become a party to UN Framework Convention on Climate Change in 2003. This convention indirectly addresses air pollution, as the main cause of the adverse effects of change in the Earth's atmosphere on human and environment. The objective is specified as "to achieve stabilization of greenhouse gas concentrations in the atmosphere at a level that would prevent dangerous anthropogenic interference with the climate system" (Article 2). Under the "Principles" section of the convention, developed country parties are required to take the lead in combating climate change and the adverse effects thereof (Article 3/1). Again, the "Principles" section requires the contracting parties to take precautionary measures to anticipate, prevent or minimize the causes of climate change and mitigate its adverse effects (Article 3/3). The contracting parties have a right to promote sustainable development and are encouraged to support sustainable development (Article 3/4). According to "research and systematic observation", which is one of the principles covered by the convention, the contracting parties shall support international and intergovernmental programs about the subject-matter. Furthermore, the "education, training and public awareness" principle emphasizes that public access to information on climate change and its effects should be provided. It is also prescribed by the convention that the contracting parties shall cooperate at the international level in: the development and exchange of educational and public awareness material on climate change and its effects; and the strengthening of national institutions and training experts in this field. A Conference of Parties is established, which shall convene at intervals to be determined by the convention and keep under regular review the implementation of the convention. In conclusion, "preventing pollution", "enabling sustainable development", "research and observation", "education", "access to information" and "cooperation" principles are covered by the convention.

In 1997, the Kyoto Protocol to the United Nations Framework Convention on Climate Change was concluded. The United Nations Framework Convention on Climate Change (UNFCCC) addresses the climate impact of the transportation sector, and the Kyoto Protocol refers even more precisely to the climate impact of aviation (Petersen 2008). The Kyoto Protocol generally aims to control the greenhouse gas emissions that are not covered by the Montreal Protocol. It aims to reduce the greenhouse gas emissions caused by human activities to below 1990 levels.

European Union (EU) issued many Directives. The EU Directive directly addressing air pollution is the Directive 2008/50/EC, which has superseded the Directives 96/62/EC, 2000/69/EC and 2002/3/EC, with effect from 11.06.2010, The Directive 2008/50/EC includes the terms "air" and "pollutant" and describes them as follows: "Air shall mean outdoor air in the troposphere" and "Pollutant shall mean any substance present in ambient air and likely to have harmful effects on human health and/or the environment as a whole". Objectives of the Directive are:

1.defining and establishing objectives for ambient air quality designed to avoid, prevent or reduce harmful effects on human health and the environment as a whole;

2. assessing the ambient air quality in Member States on the basis of common methods and criteria;

3. obtaining information on ambient air quality in order to help to combat air pollution and nuisance and to monitor long-term trends and improvements resulting from national and Community measures;

4. ensuring that such information on ambient air quality is made available to the public;

5. maintaining air quality where it is good and improving it in other cases;

6. promoting increased cooperation between the Member States in reducing air pollution (Article 1).

"Cooperation" of Member States regarding air pollution is included in the objectives of the Directive. Assessment of ambient air quality, approval of measurement systems, analysis of assessment methods, cooperation with the other Member States and Commission are among the responsibilities of the Member states. Planning is also included "Air quality plans" shall be prepared where, in given zones or agglomerations, the levels of pollutants in ambient air exceed any limit value or target value, plus any relevant margin of tolerance in each case, and "Shortterm action plans" shall be prepared where, in a given zone or agglomeration, there is a risk that the levels of pollutants will exceed one or more of the alert thresholds specified in Annex XII. In addition, "transboundary air pollution" and "informing the public" concepts are included.

\section{Air pollution in Turkish legislation}

Turkish Constitution of 1982 has provided environment right through its article 56, according to which: "Everyone has the right to live in a healthy and balanced environment. It is the duty of the State and citizens to protect the environment". The concept of environment therein is to embody all environmental components such as water, air, soil. Therefore, the provision of the article 56 can be considered as the basic principle about air pollution.

In addition to the Constitution, which is the highest norm and brings an abstract rule on prevention of air pollution, Turkish Penal Code includes concrete rules on this matter. Article 181 of the Penal Code prescribes imprisonment of those who deliberately discharges waste or residues into the air in a manner which will harm the environment. In case waste has a lasting effect, the penalties shall be increased up to twice as much as the applicable penalties.

The Environment law No. 2872, which is framework legislation, also includes provisions about air pollution and its prevention. A general frame is formed by setting the objective of the Law as follows: "to ensure preservation of the environment, which is a common asset of all living beings, through sustainable environment and sustainable development principles".

Environmental pollution is defined in the Environment law as follows: "Any kind of adverse effect on the environment that may damage the health of living beings, environmental values and ecological balance". The conditions under which the environmental pollution will be considered as existent are regulated under the article "Prohibition of Pollution". According to this article, it is forbidden to directly or indirectly discharge any kind of waste and residuary into the receiving environment, or to store, transport, send away the same, or to be engaged in similar activities in a manner that will harm the en- 


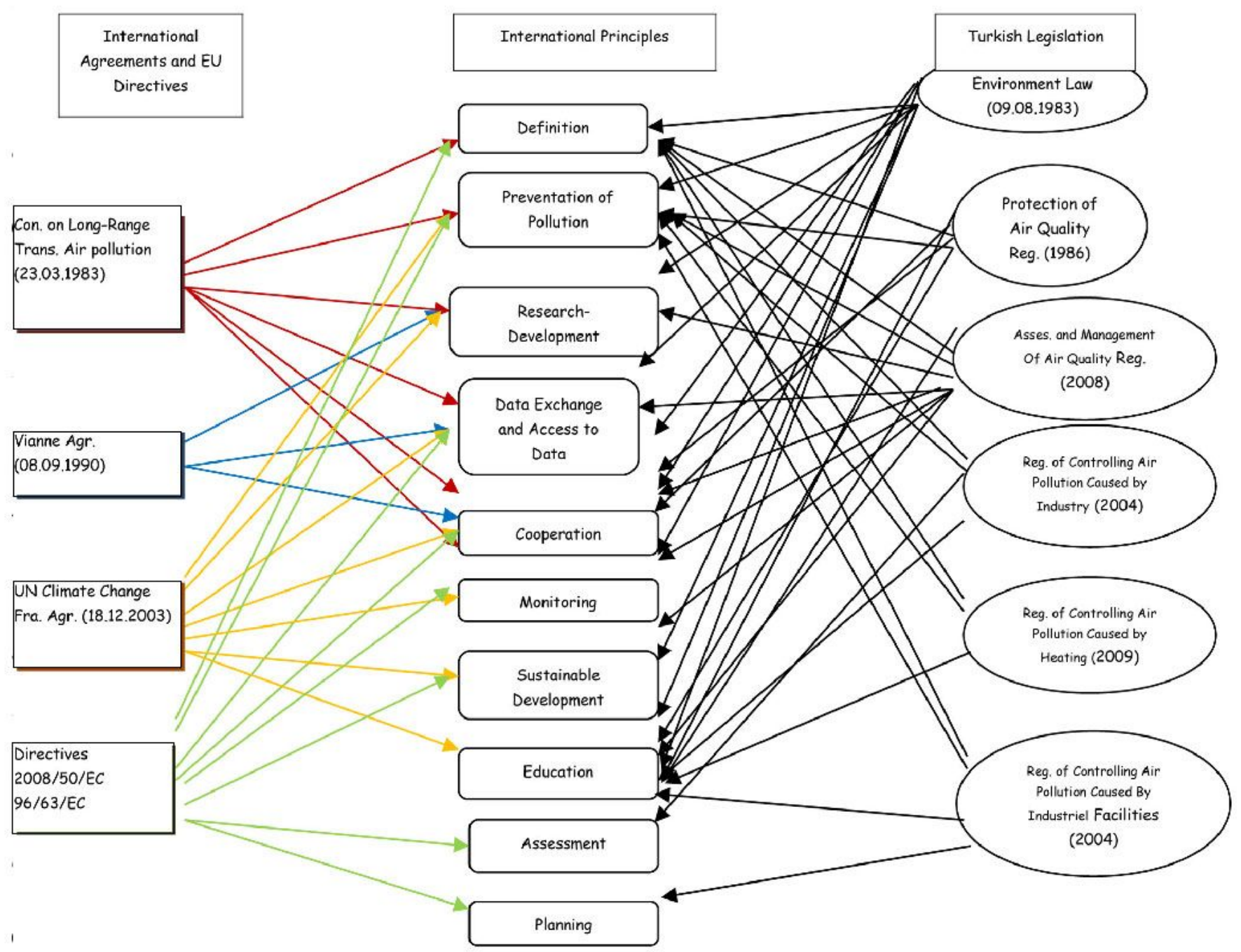

Fig. 1 - Comparison of Turkish legislation and international legislation on the basis of selected principles.

vironment or is contrary to the standards and methods stipulated in the relevant regulations. Thus, the Law which forms the general frame includes provisions relating to air pollution. Through one of these provisions, the Law prohibits "to discharge any kind of waste and residuary into the receiving environment in a manner that will harm the environment" (Article 8). However, these provisions are of a very general nature. It is convenient to include such a provision in terms of its being a framework regulation and in order to throw a light on the other regulations.

The Road Traffic Law No. 2918 of 1983 includes a provision indirectly relating to air pollution. Causing smoke and dust emission in a manner that will disturb the surroundings when driving a motorized vehicle is considered as a crime subject to a fine by the Law. Exhaust emissions are one of the important factors that cause air pollution (Erkan 1987), and it is compulsory to include an arrangement on this matter in the
Law taking into consideration the number and age of motor vehicles used in Turkey, particularly in the big cities. Turkish Standards Institution determined limit values for the exhaust emissions by relevant studies (Gürpanar 1970).

Heating is also one of the factors that affect air pollution. Air pollution has significantly decreased as a result of using natural gas as fuel. The first Law on this matter is the Authorization Law No. 3378 on Amendment of Some Laws on Natural Gas Use issued in 1987. Then, this law is superseded by the Natural Gas Market Law No. 4646 (Took effect upon publication in the Official Gazette Issue No. 24390 of 02.05.2001). Both laws share the objective "to ensure supply of good-quality natural gas at competitive prices to consumers in a regular and environmentally sound manner under competitive conditions" and to preserve environment during use of the authorization arising from the law.

Regulation on Protection of Air Quality
(Took effect upon publication in the Official Gazette Issue No.19269 of 02.11.1986), which is directly related to Air Pollution, has entered into force in order to put forth details of concrete application of the matter, for which a frame is formed under the Environment law. Objective of this Regulation is to control the smoke, dust, gas, steam and aerosol emissions that are discharged into the atmosphere as a result of any kind of activities, and to protect human and environment against any hazard that may arise from pollution of atmospheric environment.

This regulation, which includes a detailed arrangement, has set the limit values for air quality, limits of emissions for the plants that are subject to permission, limits of discharge of waste gases and limits of special emissions for high-pollution plants. The annexes to the regulation deal with the limit values for motor vehicles, measurement and determination of air pollution, special substances in dust emissions, organic steams and gases, carcinogens, determination of 
chimney height of the plants that are subject to special permission, plants for disposal of garbage and wastes, plants of soil products, foundries, acid production plants, chipboard and similar wood products manufacturing plants, oil refineries, hard coal gasification plants, bituminous road construction materials production and processing plants, graphite and similar products manufacturing plants, glass manufacturing plants, fertilizer complexes, chicken coops and stables. The places allowed and the qualifications required in connection with the said plants are dealt with in a detailed manner under the annexes.

Article 4 of the Regulation on Protection of Air Quality regulates the exceptions. The regulation will not be applicable to protection of human health and environment against nuclear fuel and radiation of other radioactive substances. At this point, the Law No. 2690 on Turkish Atomic Energy Institution (Took effect upon publication in the Official Gazette Issue No. 17753 of 13.07. 1982) has brought arrangements. In the article "Environmental Health" of this Law, it is stipulated that during performance of the duties specified in the Law, the Institution shall take the necessary measures to protect human health and environment against radiation.

Turkey has developed several communiqués about air pollution. For example, import of some substances under Montreal Convention, to which Turkey has become a party, is regulated. The Communiqué on Imports of Substances that Deplete the Ozone Layer (Took effect upon publication in the Official Gazette Issue No. 23579 of 10.01 1999 ) is in connection with this matter and prohibits import of the substances specified in the Montreal Protocol. Such substances are listed in the annexes. Also, the Communiqué on Imports of Radioactive Substances and Apparatus Using Such Substances has been published in the Official Gazette with the same date and issue number as the above Communiqué. The substances listed in the Communiqué shall be subject to a special examination by Turkish Atomic Energy Institution during customs registration process.

Furthermore, national regulations directly related to the air pollution caused by certain factors were issued. These regulations are as follows: Assessment and Management of Air Quality Regulation (2008), Regulation of Controlling Air Pollution Caused by Industry (2004), Regulation of Controlling Air Pollution Caused by Heating (2009), Regulation of Controlling Air Pollution Caused by Industrial Facilities (2004).

\section{Comparison of Turkish legislation and international legislation}

A comparison of the above mentioned international principles, which regulate air pol-

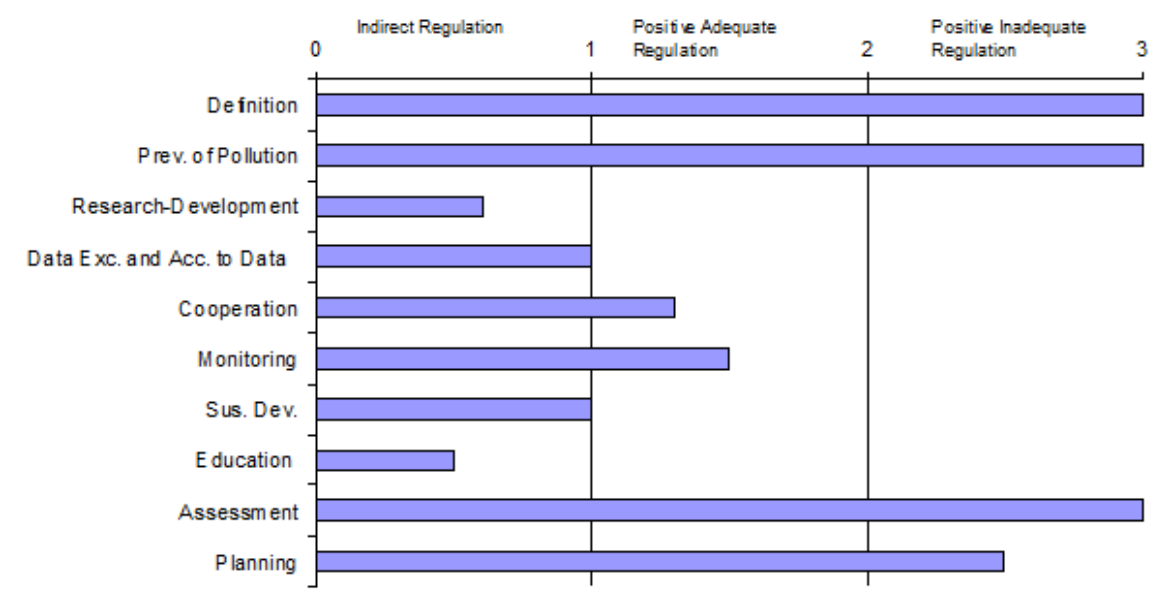

Fig. 2 - Adoption of international principles in Turkish legislation.

lution, and how they are integrated in the Turkish legislation is shown in Fig. 1. In the first phase of drawing Fig. 1, each international convention was examined and several principles were determined. Then, whether the principles within the International Legislation are included in Turkish Legislation was revealed by examining Laws and Regulations in Turkish Legislation. Thus, the principles and the international convention that include such principles, as well as Turkish Laws and Regulations that include such principles were included in Fig. 1.

As a result, nearly all international principles are included in Turkish regulations, particularly in the Environment Law and Assessment and Management of Air Quality Regulation.

As a further step in our analysis, the effect of the existing provision on prevention of air pollution has been quantified by assigning to each principle a number from 0 to 3 , namely: - $0=$ The Law does not include any arrangement about the subject matter.

- 1 = The Law includes an indirect arrangement about the subject matter.

- 2 = The Law includes a direct-but-insufficient arrangement about the subject matter. - 3 = The Law includes a direct and sufficient arrangement about the subject matter. Fig. 2 shows that the "definition", "prevention of pollution" and "assessment" principles are given full score. In other words, these principles are fully adopted in Turkish Legislation. "Planning" principle is given " 2.5 " points, which is very close to the full score. This indicates that "planning" principle is included in Turkish Legislation at a significant level. However, "education" and "research-development" principles are included in Turkish Legislation in an unsatisfactorily manner.

\section{Conclusion}

Turkey has closely followed the developments in the relevant international legisla- tion. The first international legislation related directly to the subject-matter was adopted in 1983. In the same year, the Environment Law, which includes provisions relating to air pollution, was introduced. Since air pollution has increased up to dangerous levels in recent years, implementation of some amendments and modifications to Turkish Legislation has become compulsory. As a result of this, nearly all regulations in Turkish Legislation on the subject-matter have been issued in the last six years. In Turkish Legislation, a separate regulation was issued for each factor that causes air pollution, and thereby, air pollutions caused by heating, industry and industrial plants were handled separately. Within this process, significant projects are being developed as well as the legal mechanisms that may be considered as successful. Examples are: ICP on Assessment and Monitoring of Air Pollution Effects on Forests project no.PPA/05/ $\mathrm{TR} / 7 / 7$, that was carried out in the Netherlands from 2006 to 2008; MATRA Programme, that aims at improving cooperation between the relevant ministries and institutions about 12 topics including but not limited to the environment chapter, has been carrying out together with the Netherlands government since 2004; Karabuk in the Scope of the EU Funded Environment Heavy Cost Investment Planning for Turkey Project and Kocaeli and Gaziantep Cities under Twinning Project, that were carried out together with Germany in 2003 and lasted 24 months.

Air pollution is widely covered by the national environmental regulations, in which Turkey is in the process of negotiations. It is concluded that Turkey, which is required to achieve harmonization with the EU acquis, will easily achieve this target. This is because the legal arrangements on the subjectmatter are largely harmonized with the international principles and almost all principles for prevention of air pollution are included in Turkish Legislation. Future efforts should 
focus on the "education" and "research-development" principles, which resulted to be still inadequate.

In addition, although "data exchange and access to data" and "sustainable development" principles are included indirectly in Turkish Legislation, for the level of harmonization with the international legislation is still inadequate.

A similar result was obtained for the "cooperation" and "monitoring" principles, although these principles are given a larger place than the previous ones in Turkish Legislation.

"Definition", "prevention of pollution", "assessment" and "planning" principles are supported by direct and adequate provisions in Turkish Legislation.

Based on the results of our analysis, we conclude that harmonization of Turkish Legislation with the international principles of air pollution will be not difficult despite some deficient and inadequate ways of Turkish Legislation. No serious gap or conflict with the commitments arising from the international conventions was determined. A revision of the criteria that are below the "sufficient and positive arrangement" is thus re- commended.

\section{References}

Benedick R (1998). Ozone diplomacy: new directions in safeguarding the planet. Harvard University Press, Cambridge, MA, USA

Beukel E (2003). Ideas, interests, and state preferences: the making of multilateral environmental agreements with trade stipulations. Policy Studies 24: 3-14. - doi: 10.1080/01442870308039

Erkan E (1987). Kentlerde egzoz kaynakli hava kirliligi ve Onlenmesi. TCSV Aralik Haber Bülteni, pp. 38 .

Gareau B (2008). Dangerous holes in global environmental governance: the roles of neoliberal discourse, science, and California agriculture in the Montreal Protocol. Antipode 102-130. - doi: 10.1111/j.1467-8330.2008.00572.x

Gürpanar E (1970). Cevre sorunlari, der Yayanlari, Istanbul, Turkey. [ISBN: 9753530196]

Lin C (2009). Historical review of Taiwan's environmental legislative adjustment and its implications under international agreements. US-China Law Review 6 (6): 13-25.

McFarland M (2007). 20 years of the Montreal Protocol, impact on the HVACR industry, successes to date, essential next steps, obstacles. HPAC Engineering, pp. 36-43.
Mehrotra A, Menon R, Mahajan S, Kumar KS, Rajagopal K (2009). A study on environment friendly and energy efficient room temperature magnetic refrigeration. In: "Proceedings of International Conference on Energy and Environment". Kurukshetra (India) 19-21 March 2009, pp. 770-777.

Petersen M (2008). The legality of the EU's stand alone approach to the climate impact of aviation: the express role given to the ICAO by the Kyoto Protocol. RECIEL 17 (2): 196-204. - doi: 10.1111/j.1467-9388.2008.00596.x

Serengil Y, Augustaitis A, Bytnerowicz A, Grulke N, Kozovitz AR, Matyssek R, Müller-Starck G, Schaub M, Wieser G, Coskun AA, Paoletti E (2011). Adaptation of forest ecosystems to air pollution and climate change: a global assessment on research priorities. iForest 4: 44-48. doi: 10.3832/ifor0566-004

Victor DG, Coben LA (2005). A herd mentality in the design of international environmental agreements? Global Environmental Politics 5 (1): 2457. - doi: 10.1162/1526380053243558

Woods C (2002). Meeting the Montreal Protocol: alternative fire suppression systems for archives. Journal of the Society of Archivist 23 (2): 179186. - doi: 10.1080/0037981022000006363 